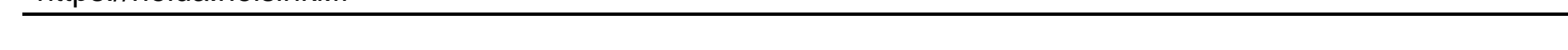

$-2$ 


\title{
Innovation Platforms: a tool to enhance small-scale farmer potential through co-creation
}

\author{
M ila Sell* ${ }^{12}$, Hilkka Vihinen ${ }^{1}$, Galfato Gabiso ${ }^{3}$, Kristina Lindström ${ }^{2}$ \\ ${ }^{1}$ Natural resources Institute Finland ${ }^{2}$ University of Helsinki ${ }^{3}$ Hawassa University
}

\begin{abstract}
This paper describes the process and analyses the results of a project in Ethiopia establishing an Innovation Platform (IP) as a tool for co-creation from an innovation systems perspective. The results are encouraging, suggesting positive effects both on yields, but more importantly on the capacity and role of participants as communicators and agents of change in the community. The IP seems promising in creating new networks and modes of communication. The importance of good facilitation, commitment by all members from the start and feedback-loops driving the process was found to be essential.
\end{abstract}

Key words: Innovation systems, Innovation platform, small-scale farmers, Ethiopia

\section{Notes on contributors}

Mila Sell is Senior Specialist and Research Scientist at the Natural Resources Institute Finland (Luke). She has a long experience in program development and coordination, teaching, and fieldwork in several African countries, focusing on multi-disciplinary research, systems approach and participatory research and extension methods, with a special focus on women empowerment in agriculture. She is finalizing a PhD in agricultural economics, combining econometric approaches with her background in folkloristics.

Hilkka Vihinen is a political scientist, specialized in rural and regional development and policy, as well as participatory approaches. Since 2003, she is Professor of Rural Policy at Natural Resources Institute Finland, Luke (formerly Agrifood Research Finland, M TT).

Galfato Gabiso is a farming system researcher in agronomy at Hawassa University and an expert in technology transfer activities. He holds an M Sc in plant Science Specialization in agroforestry from Hawasa University Since Decmber 2011 and is currently involved in several international research programs.

Kristina Lindström is professor of Sustainable development at the University of Helsinki, Finland. Her special interest is sustainable food production and consumption. She has worked on diverse aspects of biological nitrogen fixation and rhizobia for decades especially in collaborations with European, Chinese and African colleagues, the research including molecular ecology, diversity, biogeography and genomics of the rhizobium $t$ legume symbiosis. For the last ten years she also worked in Ethiopia, mapping biodiversity of rhizobia, inoculant testing and inoculation practice. 


\section{Introduction}

As a global community we are faced with a wide range of challenges in the coming decades, caused by climate change, resource scarcity and population growth. For those of us working in the agriculture and food sector, this will require new approaches, methods and technologies. In SubSaharan Africa, where the economies are dominated by small scale-farming, engaging up to $80 \%$ of the population, farmers both create livelihoods and contribute to local food security. Therefore their role is crucial when developing sustainable local food systems, in which both humans and the environment can thrive.

Actively involving small scale farmers in the innovation process will bring forth solutions that are most suitable in the local context, both in terms of the farming system and in reflecting the direction in which the local community wants to develop. Taking a holistic innovation[s systems perspective opens up possibilities to understand not only technological innovation, but innovations relating to food systems, markets, incentives, as well as local dynamics and power structures affecting these. This has the potential to create sustainable opportunities for smallholder farmers and pathways toward ecologically and socially just societies, in which women's roles and agency is recognised as assets.

Using Innovation Platforms (IP) has been a popular approach to engage smallholder farmers, in the past years (Davies 2016). Considering IPs as a methodology or tool in agricultural development and research, the operationalisation of the approach is essential. Recent attempts to analyse challenges, best practices and ways to evaluate efficiency of IPs have been useful, but more insights into practice are called for (Cadilhon 2013, Davies 2016).

The purpose of this paper is to present structured empirical experiences and an analysis of the strengths and challenges of IP as a tool to introduce new technology through a participatory process.

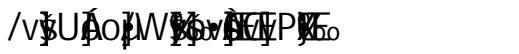

We specifically look at how the IP methodology was received in the given context, by the local community, both those participating in the IP and among other community members (question 1 ). We then look at the main strengths and challenges in implementing an IP, based on the experiences of this participatory project (question 2). Finally we discuss how the methodology could be developed further in order to better serve the needs of all stakeholders (question 3 ). This will entail integrating an end-user/co-creation perspective into the process, which may require changing the mind-set of some participants (particularly extension agents). The analysis recognizes the important role played by existing unofficial networks and looks at the dynamics between the group formed through the IP activity and these networks.

Our work is based on the outcomes of an empirical study in Ethiopia, in which an Innovation Platform was established with local farmers and other stakeholders to test and integrate new

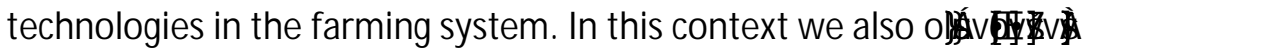
processes as agents of change, and also discuss the possible influence on the role of women that participation in the IP brought. The data collected is mostly qualitative and context specific, however, we frame our discussion so that it contributes knowledge and practical solutions that can be useful for the design of future projects as well as for policy making. 


\section{Background}

Seventy percent of people faced with persistent poverty live in rural areas, most of them smallholder famers (Röling 2010). They farm large parts of the arable land in developing countries, mostly through rain-fed agriculture. Supporting them to increase their productivity can potentially have great impact on their own wellbeing, but it can also play a significant role in tackling some of the challenges of global food security, such as availability and access to nutritious food from local sources. Although small-scale farmers are in a key positon as both producers and consumers in the food system, they also represent the most vulnerable groups, constrained by poverty, limitations in inputs, education and market access. This is especially true for women farmers, who are often even more constrained than their male counterparts, in terms of access, landownership and empowerment.

Institutional conditions have a central role to play as many of the constraints small-scale farmers are faced with are in fact not technical, but rather related to institutional pre-requisites (Adjei-Nsiah et al. 2013). This can mean lack of infrastructure, markets and access to inputs and extension services or it can be related to land ownership and the local tenure systems. State driven enabling conditions, such as fair prices, absence of corruption, strong farmer organizations, regulatory frameworks that countervail exploitative practices, need to exist in order for development to take off. This has been lacking in Africa, and it is one of the reasons why replicating the Asian green

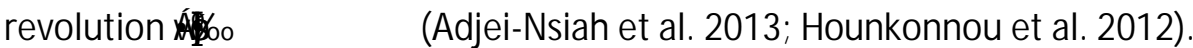

Ethiopia is a country faced with many challenges. It is one of the poorest countries in the world, although large improvements have been made in terms of poverty reduction, during the past twenty

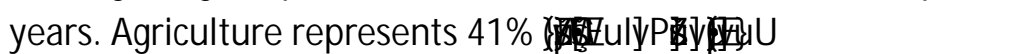
employing over $80 \%$ of the nearly 100 million population directly or indirectly (World Bank 2017). However, rural poverty remains high with diminishing farm sizes. In addition agricultural productivity is inhibited by degraded ecosystems, impeding productivity growth, causing food insecurity (Getnet et al. 2017). Agricultural soils are low in organic matter, affected by soil erosion and nutrient depletion. Fertilizer is used much below the recommended level and generally only for the major crops, such as teff, wheat and maize (Getnet et al. 2017).

The Ethiopian government has attempted to target these challenges through the Ethiopian Agricultural Transformation Agency (ATA), initiating a number of new programs to enhance technology delivery and uptake. It is widely recognized that agricultural advisory services need to be re-conceptualized as the complexity of knowledge production is better understood. Ethiopia has been a forerunner in Africa, making major investments in agricultural extension in an active effort to increase productivity of small-scale farmers, since the early 2000s (Krishnan and Patnam 2013). One of the new methods introduced through the local governance sub-administration structure, is the so-called one to five networks, where one trained farmer is responsible for sharing the new knowledge with a set group of five other farmers (Bekele et al. 2016). The system is designed to enhance collaboration, learning and problem solving, and is generally positively experienced by farmers, but critics also see the risk of it being used by the state as a controlling mechanism (Bekele et al. 2016). 
The ATA follows progress through its performance management agenda, but no official evaluation of the programs has been completed. However, according to a few scientific studies, the success of the programs has been mixed (Krishnan and Patnam 2013). This suggests there is room also for other approaches to technology transformation and productivity.

\section{Systems approach in agriculture innovation}

Central to innovation systems thinking is recognizing that innovation happens through ^ $\}$ uê $\Delta$

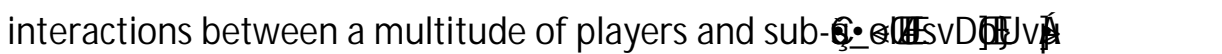

$2014,464)$. It allows for a holistic understanding of the processes involved in knowledge production, adaptation and implementation and gives a more nuanced picture of the interconnected roles of the different stakeholders, recognising their challenges and needs(Hellin and Camacho 2017; Hall and Clark 2010; Hounkonnou et al. 2012). When managed well, an innovation systems approach will allow all stakeholders, including small-scale farmers, to interact, negotiate agreements, identify promising entry points, and influence the creation of new models and opportunities (Adjei-Nsiah et al. 2013; Röling 2010).

But in order to be successful, an innovation system also requires innovation capacity of its participants, that is, human capital, skills, capacities and competences, and in many cases also new working procedures (Lilja and Dixon 2008). There are many context specific factors, both institutional and non-institutional, that influence innovation capacity. In many cases there are also gender-specific differences and concerns. Focusing on building innovating capacity of women and mainstreaming gender into the innovation process, for example through guaranteeing representation of women, is central to sustainability.

A successful innovation process requires skilful facilitation or brokering, in order to balance power and solve barriers to networking between different stakeholder groups (Klerkx, Van M ierlo, and Leeuwis 2012; Madzuzo 2011). Also the relationships within groups, or more specifically between community members within existing networks, will influence how support and information relating to agriculture and livelihoods is shared. Krishnan and Patnam (2013), who compare the effectiveness of official extension activity to learning from neighbours in adopting new technologies in Ethiopia, find that peer-effects in social networks are central to choice. Initially, when introducing a new technology, the extension agents may be influential, but very soon the importance shifts to neighbours and other community members. This demonstrates the importance of the unofficial social networks in society, as spheres where choice and change takes place.

\section{Innovation Platforms}

Use of Innovation Platforms (IPs) is an approach for actively tapping into the innovation system. IPs have become increasingly common in the past years. There is no exact definition of an IP or model for how one should be set up and run. The definition formulated depends on the application of the IP. The basic principle is that an IP can be a tool to establish connections and networks between heterogeneous actors creating a space for exchanging knowledge regarding a common problem, that is developing and identifying local solutions to local problems (Cadilhon 2013). This is a core element of the Agricultural Innovation Systems approach, in which innovation should be codeveloped through a multi-stakeholder process promoting shared learning (Klerkx, Van M ierlo, and 
Leeuwis 2012). IPs have also been used as tools for more specific or limited tasks, for example, where the goal is to tackle a concrete challenge or to promote specific technology adoption (Hounkonnou et al. 2016). It can link the local innovation system to work done by scientist, allowing farmers to participate in the whole research process.

Our IP was established with the aim of promoting the use of legume inoculation for sustainable intensification of smallholder agriculture. It was shaped as a joint discussion and training platform for farmers, extension agents, and experts, facilitated through monthly face-to-face meetings and annual workshops involving scientists and stakeholders.

But although IPs have become increasingly popular in both research and development projects, there are not many studies or frameworks for assessing their efficiency. A few good studies focusing on impact do exist and provide some suggestions on the central aspects of a working IP.

Hounkonnou et al. review a development programme using IPs in 32 different locations to identify the potential of IPs to influence institutional issues (2012). They find that in communities using IPS the innovative activity is more diverse. One of their key insights is the importance of identifying the right level and entry point for any given domain. For example when the focus of the project was pest management in cotton, the entry point was creating capacity and opportunity of farmers to use new integrated pest management. When the domain was oil palm quality, the entry point was improving value chains for small-scale women processors (Hounkonnou et al. 2012)'. However, they also conclude that the ability of an IP to generate change will depend greatly on the level at which it is working, whether at niche, regime or landscape, and whether the change is targeted at practical or institutional levels (Hounkonnou et al, 2016). The main reasons for failures, identified in the study, were linked either to members failing to institutionalise the IP in favour of projects with immediate short-term benefits, or to failure of facilitation due to confusion or lack of clarity relating to decisionmaking and roles. National political issues, including pre-and post-election security concerns were also identified as risks, again illustrating the importance of context for the success of an IP (Hounkonnou et al. 2016).

Similar issues are identified by Cadlihon and Davies et al., when assessing key factors for IP impact and success (Cadilhon 2013; Davies 2016). lệ̈ ， building \}v]oZ \} v[å conduct-performance framework, identify four interacting variables, significant for the effectiveness and performance of an IP, namely context, structure, conduct, and process. They define a theory of change for transforming impact at scale, including three interconnected change pathways; markets, intuitions and innovation capacity (Davies et al. 2016). Using this approach they study a number of IPs and their performance. They find many positive examples where IPs have created stronger networks and higher levels of trust and information sharing between different stakeholder groups. In several cases capacity of local actors increased, including that of women. An example was an IP set up in Ghana to support mixed crop-livestock systems, through which women got involved in decision-making regarding livestock sales, previously considered a male activity (Davies et al 2016).

A key insight of Davies et al. was, however, the highly context-specific nature of IPs. In addition to a conducive context, some level of innovation capacity is also required of participants, in order to be able to participate actively in an IP. But participation also provides knowledge, new skills and opportunities, through which participants may acquire new roles as innovators and communicators in the community. Therefore, participation can build or reinforce innovation capacity. Compared to 
other extension methods, the IP approach has potential to better supports co-innovation, learning and empowerment processes which can make it a better tool of the systems approach.

\section{Analytical framework}

Based on the theoretical background described above we have developed an analytical framework (Figure 1) to structure the different aspects of an Innovation Platform, described in this paper, and to respond to our three main research questions concerning (1) the reception of IP as a tool, its strengths and challenges (2), and how to improve the methodology (3). Our framework builds on innovation systems thinking, suggesting that for new technology to be sustainably integrated into a farming system requires different community stakeholders engaging through a participatory approach. Both existing farming practices and networks in the community will influence the process. But through the IP[êtesting and feed-back loops, new technology can be developed and integrated in a context specific way. The IP activity itself is not hermetic but influences also other aspects in society in addition to farming, through the new networks, modes of communication and capacity of participants it creates. These new assets in turn may reflect back on the activity of the Innovation Platform, through strengthened innovation capacity, making it a reflexive innovation process.

In Figure 1 the blue coloured boxes represent the current, context-specific situation, that is, existing farming systems, networks and information channels. The green is the Innovation Platform activity itself, while the red boxes represent the outcome of the process and the new communication models and agricultural practices it has contributed to.

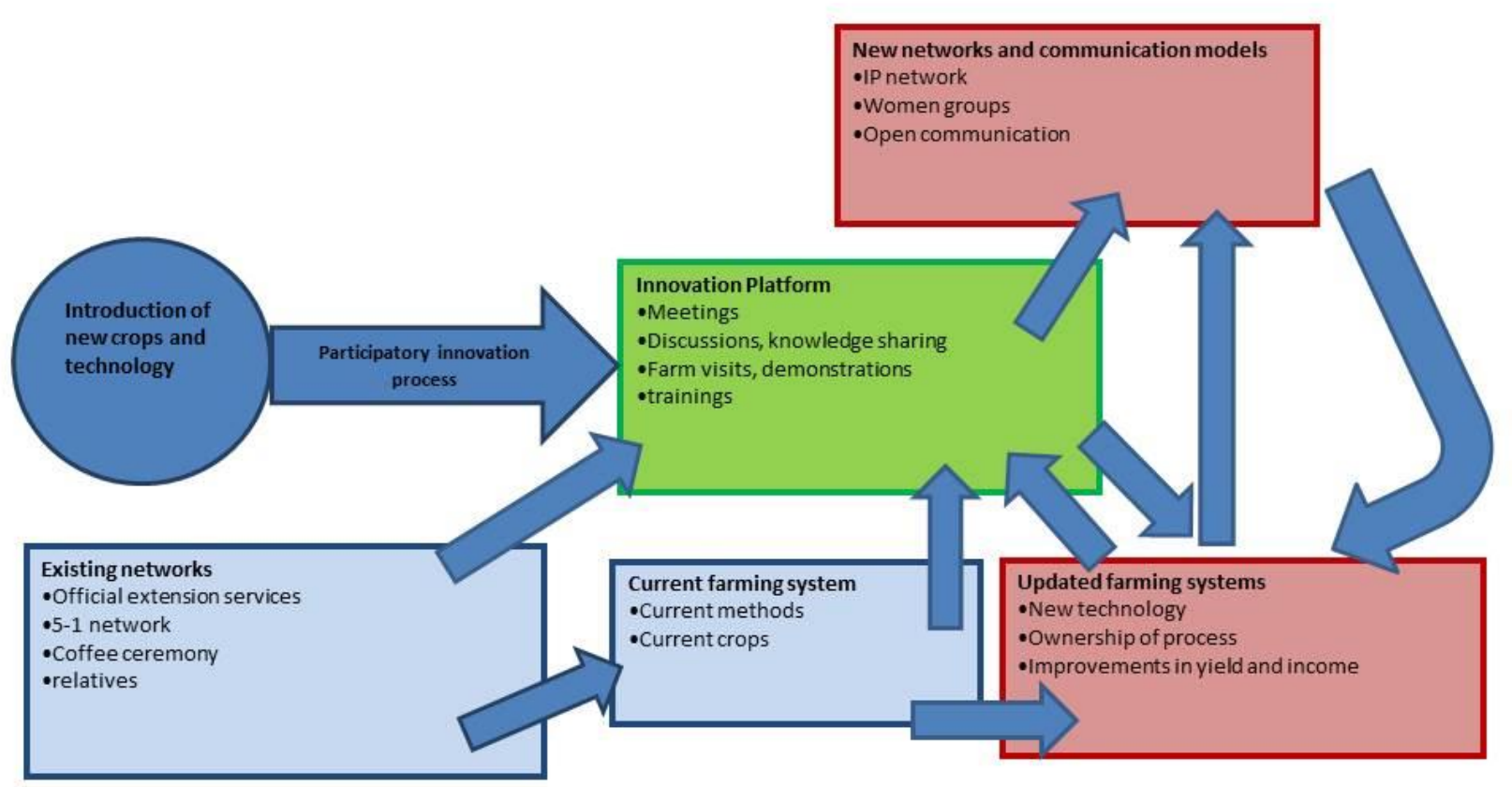

Figure 1. Analytical framework 


\section{Case description and methodology}

Ethiopia is a country of multiple different climatic zones and farming systems. Our study area is

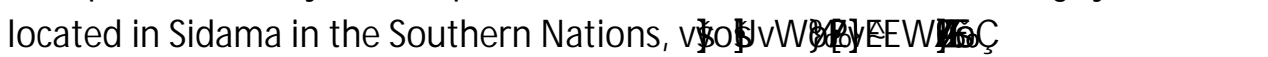
$270 \mathrm{~km}$ south of Addis Ababa in the Rift Valley ( Figure 2). The area is characterized by semihighlands, with very small average farmland sizes. Among the households in our study the average farm is 0.8 hectare, $77 \%$ having one hectare or less (Table 1 ).

Table 1. Farmsize of study households

\begin{tabular}{lcc} 
Farm size & Freq. & Percent \\
\hline Less than 0.5 ha & 21 & 35.00 \\
0.5 to 1.0 ha & 25 & 41.67 \\
1.0 to 2.0 ha & 8 & 13.33 \\
2.0 ha or more & 6 & 10.00 \\
\hline Total & 60 & 100.00
\end{tabular}

While farm size is small, household size is still quite large, causing additional constraints. In our survey, persons who had lived at least half of their time together with the household in the past year, where considered family members. In our data the mean household size is 6.6 persons, ranging from two to 11 . The mean number of children is 3.4 .

Legumes are a central part of the local diet in Ethiopia. M any households have minimal access to meat and dairy products and legumes therefore represent the main source of protein. Legumes have the added advantage being able to fix nitrogen from the air when inoculated with Rhizobiumbacteria, improving plant growth and conserving soil fertility (Franche, Lindström, and Elmeric 2009). Using biological nitrogen fixation (BNF) as biofertilizers provides farmers with an option to chemical fertilizers, which is a climate friendly practice that is also economically beneficial.

Among our survey households, few grew only legumes on their plots. Intercropping with other crops was common. This suggests the use of rhizobium may have an advantageous effect also on the intercropped plants. When reporting the main crop on their plots, only $14 \%$ had plots designated specifically to common bean, although a majority grew them. The most important food crop was enset"ii, grown by $71 \%$ of households, followed by maize, grown by $47 \%$. The most important cashcrops were chat and coffee, grown by $90 \%$ and $76 \%$ of households respectively. 


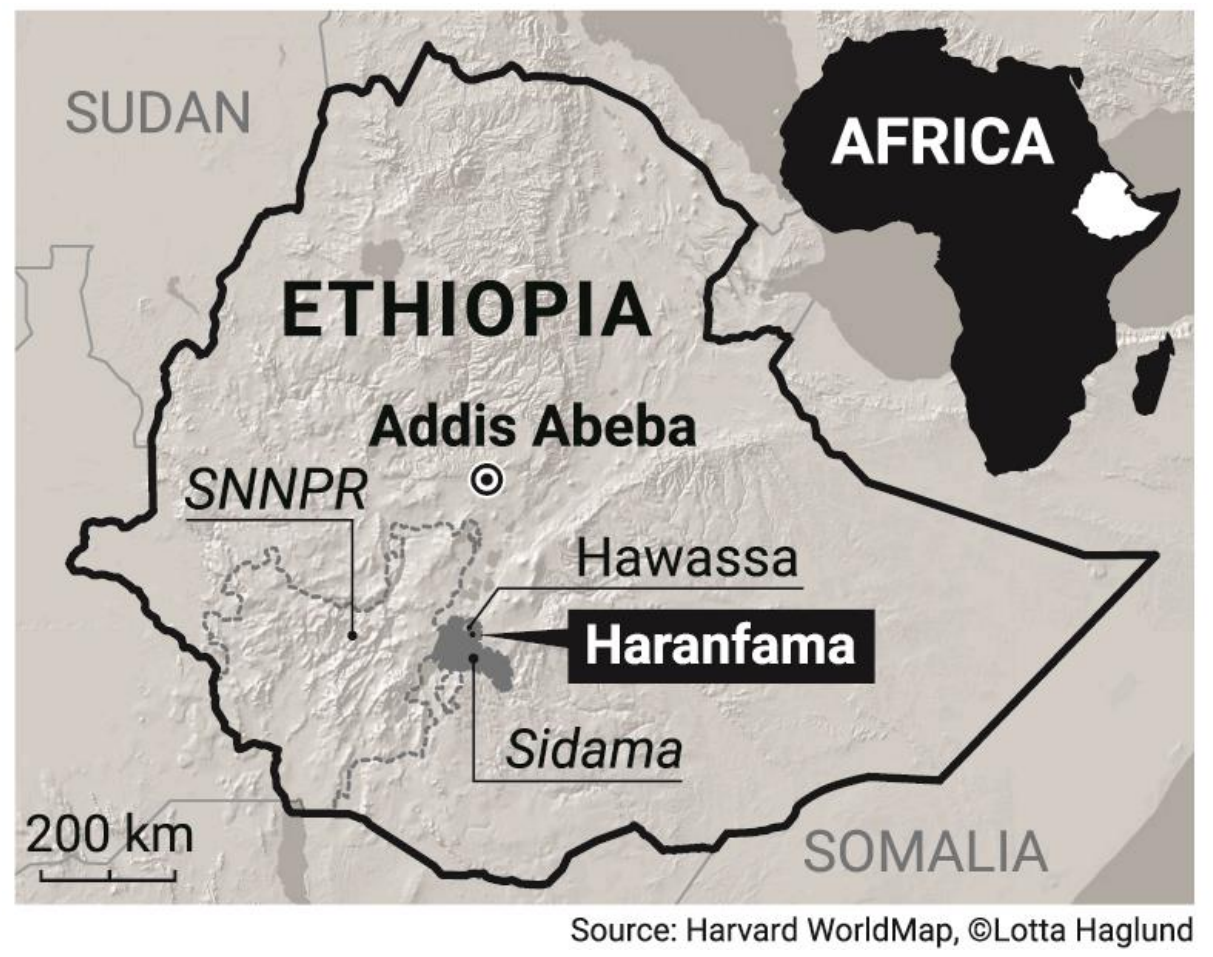

Figure 2. M ap of Ethiopia

The project, implemented by a multi-disciplinary team from Finland and Hawassa University, was based on a long-standing collaboration around rhizobia technology. Using inoculants with legumes as a bio-fertilizer was considered promising in improving both yields and soil quality. The IP process was one component of the multi-dimensional project, to facilitate the integration of legume and rhizobium technology into the farming system, through an interactive process of sharing information, testing and development by local stakeholders $s^{\mathrm{iii}}$. The study focused on the process, trying to capture how the IP activity was experienced by the community, both members and nonmembers, as well as their contribution to the innovation process. We also wanted to identify the effect participation had on uut own experience in terms of farming practices, visions for the future, and role in the community, especially that of female members. Based on this information the study attempts to identify the strengths and challenges of the IP approach in order to provide suggestions for future development of the methodology.

Data was collected throughout the project by different means (Table 2). The project started with a formative research phase to identify the most prominent farming systems and other context specific factors of the community, including gender roles. We completed a comprehensive household survey of sixty households in four villages, in two Kebelles (ward) in the Tula Woreda (district) close to Hawassa city. Data collected in the survey included an overview of farming systems, amounts of inputs and yields, information about family members as well as their age, educational level and main activity. This gave a good overview of the area, the farming systems and the main sources of livelihood.

Focus group discussions with a group of six to seven women were conducted in each of the villages to discuss activities and roles of women in agriculture and in the community as a whole. The 
(\}解vi\}uv[率o

s in decision-making. We also discussed how opinions are changing, how the women see their future and what their hopes are for their daughters.

Table 2. Data collected in the project

\begin{tabular}{|c|c|c|c|}
\hline $\begin{array}{l}\text { Activity/data collection } \\
\text { method }\end{array}$ & Source/ Participant & $\begin{array}{l}\text { Type of information/ data } \\
\text { collected }\end{array}$ & $\begin{array}{l}\text { Responds to research } \\
\text { question }\end{array}$ \\
\hline $\begin{array}{l}\text { Formative research - } \\
\text { household survey }\end{array}$ & 60 households & $\begin{array}{l}\text { Overview of current farming } \\
\text { systems }\end{array}$ & Background information \\
\hline Focus group discussions & 4 groups of 6-7 women & $\begin{array}{l}\text { t\}uv[ }[\hat{\Phi} \mathrm{A}]\} \vee \hat{\boldsymbol{e}} \\
\text { experiences of current farming } \\
\text { systems and their role in them }\end{array}$ & Background information \\
\hline $\begin{array}{l}\text { IP meetings approx. } \\
\text { 1/month/Report }\end{array}$ & $\begin{array}{l}12 \text { farm households, } 6 \\
\text { extension agents } \\
\text { (second year } 18 \\
\text { households) }\end{array}$ & $\begin{array}{l}\text { Meeting reports of the most } \\
\text { important themes discussed, } \\
\text { questions raised and solutions } \\
\text { suggested }\end{array}$ & Question 2 \\
\hline $\begin{array}{l}\text { Workshops/training } \\
\text { sessions 1-2 times/year }\end{array}$ & $\begin{array}{l}\text { IP members, experts } \\
\text { from different fields, } \\
\text { incl. Finnish project } \\
\text { team }\end{array}$ & $\begin{array}{l}\text { Workshop relating to specific } \\
\text { theme or to discuss questions } \\
\text { raised by the IP, e.g. soybean } \\
\text { cooking and nutrition workshop. }\end{array}$ & Question 2 \\
\hline Post-intervention survey & 60 households & $\begin{array}{l}\text { Households revisited to get } \\
\text { feedback on the project from } \\
\text { both IP members and non- } \\
\text { members }\end{array}$ & Question $1 \& 2$ \\
\hline Key informant interviews & $\begin{array}{l}2 \text { female IP members, } 2 \\
\text { male IP members and a } \\
\text { community manager }\end{array}$ & $\begin{array}{l}\text { post-intervention interviews on } \\
\text { the experiences and effects of } \\
\text { the project/IP activity for } \\
\text { members and larger community }\end{array}$ & Question 3 \\
\hline \multicolumn{4}{|l|}{ 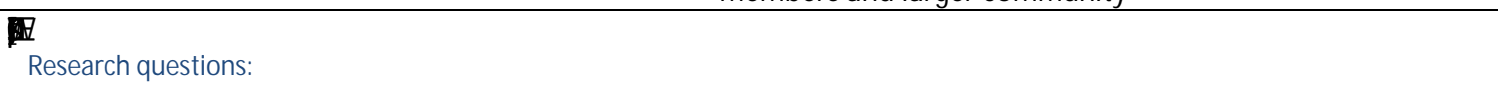 } \\
\hline \multicolumn{4}{|c|}{$\begin{array}{l}\text { 1. How was the IP approach experienced and received by the local community (both members and non-members)? } \\
\text { 2. What were the main strengths and challenges of the approach in the given context? } \\
\text { 3. How can the methodology/approach be developed further to serve the purpose of being a co-creation tool of the innovation } \\
\text { system? }\end{array}$} \\
\hline
\end{tabular}

The IP was then set up and twelve of the households from the survey invited to participate. In the second year of the intervention an additional eight households were included in the IP. A criterion for participation was that both spouses take part in all meetings. Also local extension agents were members of the IP, which was facilitated by an extension expert from Hawassa University. The IP met approximately once a month. The meetings included discussions about issues raised by IP members, including challenges relating to farming, but also suggestions for improvement. Demonstrations, farm visits and visits by experts were also organised for the group. IP meeting reports were compiled by the facilitator after each meeting, summarising participation, the issues discussed, the atmosphere of the meeting and any specific requests or suggestions. The themes and challenges brought up by members of the IP were fed back into the project, as a central aspect of the process was adapting the activities based on the needs and suggestions expressed by IP

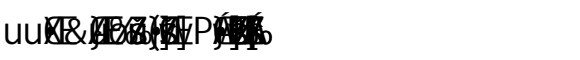

A thematic workshop was organized each year. Themes included a nutritional training and soybean cooking workshop. Again, they were based on the requests and interests of participants. The participants were given biofertilizers developed from indigenous rhizobia strains for the particular crop (Aserse et al. 2012). In addition they were given seed, both common bean, which is one of the staple crops in the area and soybean which was new to the farmers. All the activities organised and the support given to members of the IP, served as part of the approach. Evaluating 
the impact of this is part of research question two, that is, identifying the main strengths of the methodology.

At the end of the two year implementation phase, the 60 households took part in a postintervention survey, focusing on changes in farming practices as well as possible changes in household well-being more generally. One part of the survey focused specifically on the IP activity, how it was experienced by the members, what changes it had brought and how the members now viewed their future.

As a measure of triangulation $t$ combining multiple empirical materials or methods $t$ we also conducted five key informant interviews post-intervention, to get a different perspective on the IPS. The interviews bring both depth and flavour to the survey responses. They allow for a better insight ]v IP members, two of them men and two women. The fifth informant was a manager in the area, closely engaged with the project, but also very knowledgeable about other issues in the community, as well as previous initiatives and projects carried out. The interviews focused on how knowledge and innovation spread in the community, and the roles of different actors in this process, the key challenges farmers face in terms of adopting new technology and how the IP was experienced by and affected the community.

The survey data were collected through questionnaires by five master-level students from the University of Hawassa in the local language sidamina. Results were entered into a database and statistically analysed using Stata 14 software. The survey questions, focusing on the most positive and negative aspects of the IP, were designed to capture how the IP was experienced by participants. Several questions also focused on the dynamics within the IP as well as in relation to the community outside. Through this line of questions we tried to capture possible conflicts or challenges that may have existed or developed within the group, including hierarchy or power issues, and how these may have changed during the course of the activity.

The interviews were conducted by one of the Finnish social-science team members, in collaboration with a representative from the University of Hawassa, who also had the role of interpreter, making the interview situation an interactive discussion. As the bulk of the analysis work was done at the Finnish end, it was the English version of this discussion that was transcribed. Key themes re-occurring in the individual interviews as well as in the survey were identified. Like Davies

öX 溜 content driven approach to thematically analyse the information emerging from the data (Guest et al 2012). This is an inductive method using an exploratory approach to the data, rather than predetermining themes or categories. The IP meeting reports, produced in English by the facilitator, were also reviewed to detect patterns and central issues raised by the participants, which are described in the following section.

\section{Findings}

\section{Experiences by the local community of the IP approach (question 1)}

The survey data was analysed to respond to research question one. The farm household intervention

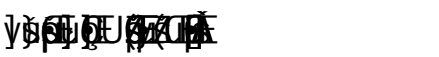


regarding the effectiveness of the technology ${ }^{i v}$. One of the questions asked in the post-intervention survey was whether yields had increased, stayed the same or decreased compared to two years prior. Forty-two percent of the respondents reported smaller yields, the main reason being drought. This is not surprising as the year 2016 was particularly dry in Ethiopia with devastating effects on large areas, although Sidama was not one of the worst affected areas. However, a clear difference in responses could be seen between the respondents who had been part of the IP and those who had not. Eighty-eight percent of those who reported smaller yields had not been part of the IP, while $71 \%$ of those reporting higher yields had been participants. Out of all IP members $60 \%$ reported higher yields. These responses likely reflect the result of the technology itself, but it also reveals a positive and optimistic attitude among IP participants.

Part of the technology offered to IP participants was growing soybean, which was new to the area. In the post-intervention survey $34 \%$ of respondents reported changes in the crops they grew, most had started planting soybean. Interestingly three households not part of the IP also reported growing soybean. This indicates that the information from the IP has spread in the community. This suggests the IP may have an impact for the wider community, rather than being limited to participants. It will be discussed further relating to the strengths of the methodology.

The most important aspects of being part of the IP reported in the survey were the knowledge, experience and advice the participants gained, as well as the concrete technology - the biofertilizer they were given. All respondents also mentioned their role in the community had changed. Most stressed the fact that they had become model farmers or otherwise had the opportunity to share the new experience with others in their community. The importance of this new status or role was found both in the responses of the men and the women". All of the IP members said they were optimistic about the future and felt their capacity had greatly improved and they were now better equipped to deal with future challenges. Sixty-four percent stated that they expected their income to increase over the coming years, or that they would be more productive.

M ost of the IP members were very actively engaged in the project and contributed ideas and suggestions. One suggestion was setting up control plots to concretely visualize the effect of the inoculant. This was done in the farmers training centre, but one of the extension agents removed the control plot due to poor growth. This was very disappointing to the IP members and reflects one of the challenges of facilitating a functioning IP. Many of the members however set up also their own control plots on their very limited farmland, which shows their positive engagement in the project.

\section{Main strengths and challenges of the IP approach (questions 2)}

Based on our post-intervention data it becomes clear that the participants of the IP have had an important role as active members, influencing the IP process. The meetings provided a new forum for discussion and participation, different from other forms of extension activity. M ost of the IP members were very engaged in the project, and helped spread the information also within the wider community through existing networks and relationships. Some of the forums where information is traditionally shared in the community, both within religious groups, informal coffee ceremony and the more formal 5 to 1 network, in a sense became extensions of the IP. This could be seen for example through the fact that also $45 \%$ of non-IP members taking part in the survey reported that 
they expected their income to increase over the coming year. The optimistic attitude and experiences of the IP spread in the community beyond the group of IP members.

However, the high expectations created through the IP activity can also be a risk of the methodology. For example the case where the extension agent removed the control plot causing disappointment and negative feelings among IP members, reflects the risk of conflict if members have different levels of expectation and engagement. This highlights the importance of engaging all central stakeholders as peers in the process from the start, in order to guarantee ownership. It has to be a learning process for all involved where each will have to adapt to new and changing roles and modes of operation. This is perhaps the most challenging aspect of the approach, as there may be resistance towards change among some actors in the community.

This also highlights how essential skilful facilitation of the IP process is. In our case the facilitator led the meetings in a way that empowered participants to express their opinions. $\left.{ }^{\wedge}\right] v \widetilde{z} u \not \emptyset \mathrm{v} P$ of the platform is democratic, the leader of the platform gives equal chance to participants. So we

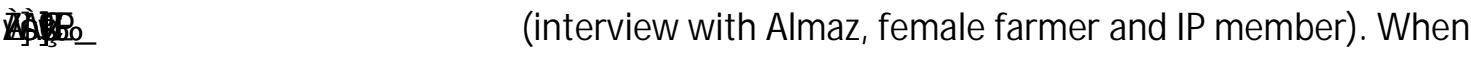
properly implemented good facilitation can prevent conflicts and provide a non-hierarchical environment, where both men and women feel comfortable to participate as active members and share their views and suggestions. Sharing of ideas is central for co-creation and also works as an avenue to empower all members. This is why we were interested in looking at the IP approach also

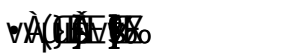

Both through the initial focus group discussions and the interviews it became clear that the role of women in the community is going through a change process. There is awareness of the importance of equality and providing women with opportunities. In reality, however, both farming and decisionmaking is still very male dominated. Women generally do not have their own plots, but assist the men on their plots and perhaps farm in between the rows on these plots, mainly beans, cabbage, potato and pumpkin for home consumption. The growing of cash crops is mainly done by the men (FGD). However, many women did report having their own risk-mitigation measures. These included diversification, increasing their productivity, or starting small-scale entrepreneurship, such as processing maize powder, making biscuits or a small shop or coffee shop.

The key informant interviews confirm that the women participating in the IP process indeed benefited from it. Their skills and capacity as communicators improved and they were more likely to

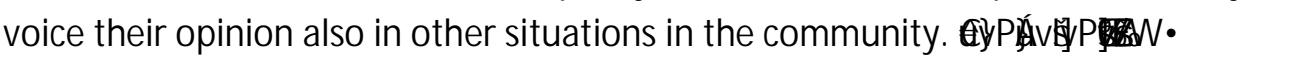
there is a change of role, especially in communication and participation. The communicating skill is improving_ (interview with Hanna, member of IP and Kebelle leader group).

\section{How can the IP approach be developed further as a tool of the innovation system (question 3)}

According to all of the key informants the IP meetings went through a major change-process during the course of the program. Initially the meetings were facilitated according to an agenda set by the facilitator. Towards the end of the project the role of the facilitator changed to observer, as the members took charge of the discussions, which ranged far beyond agriculture to issues relating to business, education and health. 


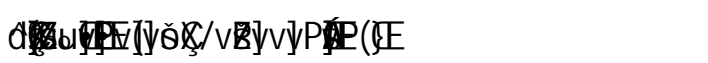

agendas, but now we cannot wait any agenda from the leader $t$ any member of the IP

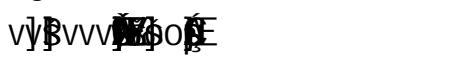

related the technology provided to us by the program, but now we are not limited to the technology, but we[ P $\}$

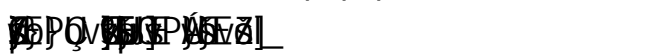

(interview with Shifara, male farmer and IP member).

As the IP activity proceeded we found that new concerns raised through the activity indeed triggered new or different needs for support (Kilelu, Klerkx, Leeuwis 2014). Although the project attempted to use the Innovation Platform as a tool to engage different community stakeholders, focus was on the farmers, the most important target group for the technology. However, we found that the participation of extension agents was central. Although the farmers were the most active members of the IP, suggesting new ideas and solutions, the extension agents are central for the sustainability of the project. Reflecting back on the case where the demonstration plot caused conflict, suggests taking on new roles may be challenging for some participants. Therefore, this needs to be an integral part of the IP design from the start. Facilitating this process carefully is perhaps the most important aspect of developing the methodology further. Therefore training extension agents as facilitators, not acting from a higher position in the hierarchy, needs to be at the centre of the approach, in order to develop the local extension system into a more inclusive direction.

One approach is to recognise the role of extension agents as experts. For example a technology such as using Rhizobium inoculants as biofertilizers, as in the current case, requires training of farmers, and therefore skilled trainers. Taking on the role as trainer can provide new opportunities for the extension agents, which can be motivating and rewarding.

\section{Discussion and conclusions}

The goal of our study was to analyse the Innovation Platform as a tool for community co-creation from a participatory innovation systems approach. We focused on how the IP methodology was received by the local community, what the main strengths and weaknesses of the approach were, and based on these results, in the context of the specific case study, identifying lessons learned and suggestions for developing the method further.

We found that if well managed, the IP process builds capacity of all participants to co-create methods that respond to context specific needs. This requires functioning feedback loops and commitments. Extension agents will be able to improve their own work to support farmers, if they internalise the benefits of empowering farmers to actively participate in the innovation system. This is part of understanding the reflexive nature of the IP process; how the IP activity can trigger the creation of new networks, or using existing ones in new ways within the community. This is likely one of the major strengths of IPs compared to traditional extension models including short-term trainings or demonstrations for groups of farmers. In comparison to the commercial village project studied by Kilelu et al (2014), which found quite a few challenges in terms of gaps and conflicts between groups, the IP may have the additional benefit of being smaller and easier to manage. This 



